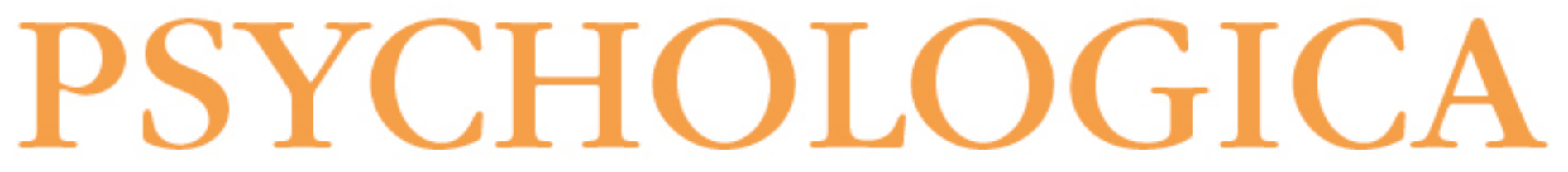

O corpo e suas narrativas: envelhecimento feminino e culto ao corpo

Autor(es): $\quad$ Vilhena, Junia de; Novaes, Joana de Vilhena

Publicado por: Imprensa da Universidade de Coimbra

URL

persistente: URI:http://hdl.handle.net/10316.2/5425

DOI: $\quad$ DOI:http://dx.doi.org/10.14195/1647-8606_50_5

Accessed : $\quad$ 26-Apr-2023 12:33:47

A navegação consulta e descarregamento dos títulos inseridos nas Bibliotecas Digitais UC Digitalis, UC Pombalina e UC Impactum, pressupõem a aceitação plena e sem reservas dos Termos e Condições de Uso destas Bibliotecas Digitais, disponíveis em https://digitalis.uc.pt/pt-pt/termos.

Conforme exposto nos referidos Termos e Condições de Uso, o descarregamento de títulos de acesso restrito requer uma licença válida de autorização devendo o utilizador aceder ao(s) documento(s) a partir de um endereço de IP da instituição detentora da supramencionada licença.

Ao utilizador é apenas permitido o descarregamento para uso pessoal, pelo que o emprego do(s) título(s) descarregado(s) para outro fim, designadamente comercial, carece de autorização do respetivo autor ou editor da obra.

Na medida em que todas as obras da UC Digitalis se encontram protegidas pelo Código do Direito de Autor e Direitos Conexos e demais legislação aplicável, toda a cópia, parcial ou total, deste documento, nos casos em que é legalmente admitida, deverá conter ou fazer-se acompanhar por este aviso. 


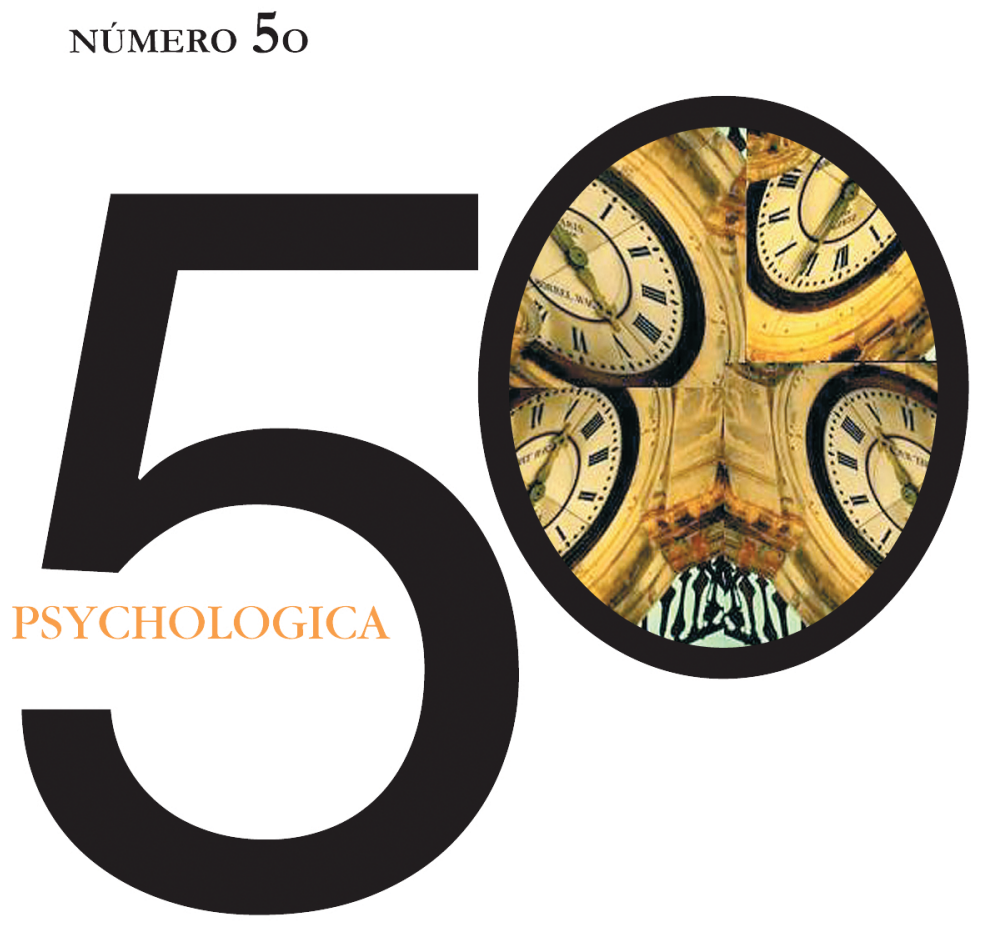

IMPRENSA DA UNIVERSIDADE DE COIMBRA

FACULDADE DE PSICOLOGIA E DE CIÊNCIAS DA EDUCAÇÃO DA UNIVERSIDADE DE COIMBRA 


\title{
O corpo e suas narrativas. Envelhecimento feminino e culto ao corpo'
}

Junia de Vilhena² \& Joana de Vilhena Novaes ${ }^{3}$

"Eu fiz um acordo de coexistência com o tempo: nem ele me persegue, nem eu fujo dele... Um dia a gente se encontra".

Mário Lago

\begin{abstract}
Na cidade do Rio de Janeiro é cada vez maior o número de mulheres maduras que procuram academias de ginástica e clínicas de cirurgia plástica como forma de manterem-se jovens e com o corpo considerado adequado e atraente. A exacerbação do culto ao corpo na cultura carioca tem levado um grande contingente de mulheres a práticas corporais cada vez mais radicais. Incentivadas pela mídia e pelo discurso médico estas mulheres são levadas a encarar o envelhecimento, apenas como uma questão hormonal ou estética, deixando de lado os aspectos subjetivos do envelhecer. $\mathrm{O}$ artigo busca fazer uma análise desta busca frenética pelo corpo ideal tomando como eixo condutor as diferenças existentes entre o corpo da medicina, visto como um organismo, da ordem da natureza, e o da psicanálise que demanda uma narrativa que signifique as experiências do sujeito.
\end{abstract}

PALAVRAS-CHAVE: Culto ao Corpo; Menopausa; Envelhecimento; Mulher; Psicanálise.

1 Pesquisa financiada pela Coordenação de Aperfeiçoamento de Ensino Superior - CAPES

2 Psicanalista. Doutora em Psicologia. Professora do Programa de Pós Graduação em Psicologia Clínica da Pontifícia Universidade Católica do Rio de Janeiro-PUC-Rio. Coordenadora do Laboratório Interdisciplinar de Pesquisa e Intervenção Social-LIPIS da PUC-Rio. Pesquisadora da Associação Universitária de Pesquisa em Psicopatologia Fundamental. Pesquisadora correspondente do Séminaire de Recherches.CRPM Pandora, Universidade de Paris VII Denis-Diderot. Bolsista da Coordenação de Aperfeiçoamento de Pessoal de Ensino Superior-CAPES.

www.juniadevilhena.com.br E-mail: juniavilhena@terra.com.br

3 Psicanalista. Pós-Doutora em Psicologia Social (UERJ). Doutora em Psicologia Clínica (PUC-Rio). Pesquisadora Universidade Estadual do Rio de Janeiro. Coordenadora do Núcleo de Doenças da Beleza do Laboratório Interdisciplinar de Pesquisa e Intervenção Social, LIPIS da PUC-Rio. Pesquisadora correspondente do Centre de Recherches Psychanalyse et Médecine - CRPM-Pandora. Université Denis-Diderot, Paris VII. www.joanadevilhenanovaes.com.brE-mail: joananovaes@terra.com.br 


\section{Introdução}

Iniciamos este artigo com uma pequena história. Alguns anos atrás, uma conhecida psicanalista francesa, de 63 anos, foi convidada para dar uma palestra em uma sociedade de psicanálise no Rio de Janeiro. Viúva há cerca de dois anos, contava para uma platéia amiga que, vivido um difícil período de luto, estava agora pronta para viver um novo amor. A confissão, dita de forma emocionada e franca, provocou distintas reações na platéia -, felizmente, não verbalizadas. Sobre uma delas vamos nos deter. Trata-se da perplexidade gerada pela assunção da sexualidade em uma mulher com mais de sessenta anos.

Talvez para os leitores europeus isto não faça muito sentido, visto que, quando comparados, o Brasil e grande parte dos países europeus encaram a velhice de formas absolutamente distintas. Do cabelo grisalho às diferentes formas do trajar, para o observador minimamente sensivel, podemos facilmente perceber as diferentes representações que o corpo maduro assume nas duas culturas. $\mathrm{E}$ é sobre a relação com o corpo na maturidade, na cidade do Rio de Janeiro, que gostaríamos de nos aprofundar.

Por que no Rio de Janeiro? Porque acreditamos que por ser uma cultura de praia, antiga capital do país, com um ethos ligado ao divertimento, o Rio de Janeiro se configura como um cenário particular, onde o culto ao corpo não apenas floresceu, como se transformou em uma das maiores fontes de regulação social do corpo feminino, como veremos mais adiante.

Das academias de ginástica e dança que proliferam, dos anabolizantes que são consumidos como balas, das lojinhas naturais que prometem saúde perfeita, às inúmeras práticas de trabalhos corporais, o corpo passou a ocupar um novo lugar em nossa sociedade e, conseqüentemente, em nossa estruturação psíquica. Cultivar a beleza, a boa forma e a saúde apontam para uma nova ideologia que se impõe como um verdadeiro estilo de bem viver.

Revistas especializadas, de saúde à moda, nos ensinam qual o corpo que se deve ter e desejar - como atingir este ideal e como utilizá-lo da forma mais eficaz. 0 corpo, assim visto, passou então a ser o passaporte para a felicidade, bem-estar e realização pessoal.

Da moda do corpo ao corpo da moda, o corpo natural se desnaturaliza ao entrar em cena. $O$ estudo sobre a concepção e codificação do corpo na cultura moderna revela, simultaneamente, que um outro olhar e uma atenção diferenciada estão relacionados às mudanças dos códigos sociais.

José Gil (1980), filósofo português, refere-se ao corpo enquanto uma "infralíngua" em comunicação com o mundo - porque fala. No palco da cultura, à mercê de 
seus signos, o corpo ultrapassa os limites do biológico - sua versão mecânica torna-se personagem/ator social travestindo-se de seu aparato simbólico. Assim ele espelha e, simultaneamente, se constitui. Se o imaginário cultural engendra gestos, posturas, hábitos, vícios, expressões, enfim, toda uma cartografia corporal que insere e reconhece o sujeito como membro de um grupo social, qual seria, na cultura atual, um dos maiores símbolos de inserção? Ter o corpo da moda.

E o que significa, na contemporaneidade, ter um corpo da moda? Um corpo aceito socialmente, esteticamente agradável aos olhos, em uma sociedade com cada vez mais telas e menos páginas? Mais ainda, o que significa para a mulher a obrigação de ser bela?

Há um conhecido ditado popular que diz que a mulher brasileira não envelhece -, fica loura. Temos notícia que, depois da sociedade americana, o Brasil tornou-se campeão nas cirurgias plásticas de cunho estético e que o botox e os preenchimentos para rugas já fazem parte da rotina "de asseio" de um imenso contingente de mulheres. Se este fenômeno nos aponta para um corpo com marcadas características da classe social (Malysse, 1987), é interessante informar que há pelo menos um hospital, na cidade do Rio de Janeiro, que atende pacientes de baixa renda para cirurgias plásticas puramente estéticas e não reparadoras como de praxe.

Sabemos que historicamente a imagem de mulher se justapõe com a de beleza e, como segundo corolário, a de saúde (fertilidade) e juventude (Remaury 2000). A contemporaneidade, contudo, parece ter exacerbado, levado mesmo ao paroxismo, tais representações. As imagens refletem corpos super trabalhados, sexuados, respondendo sempre ao desejo do outro, ou corpos medicalizados, lutando contra o cansaço, contra o envelhecimento ou mesmo contra a constipação.

Implícita está a dinâmica perfeição/imperfeição, buscando atender aos mais antigos desejos do ser humano, conforme narram os mitos, os elixires e fontes de eterna juventude.

Beleza exterior e saúde, aparência exterior desagradável e doença, cada vez mais se associam como sinônimos, no tocante às representações do corpo feminino. A questão tradicional, aceitar ou não o corpo recebido parece ter se transformado em - como mudar o corpo e até que ponto? Interessa-nos, no momento, discutir esta relação com o envelhecimento.

Em extensa pesquisa realizada em academias de ginástica, consultórios e clínicas de cirurgia plástica, Novaes (2006) investigou qual a representação social da feiúra. Segundo a autora duas características apresentavam-se como constantes na busca de um corpo perfeito: manter-se magra e jovem. Gordura e velhice eram, nas falas das entrevistadas, características que se não pudessem ser totalmente 
eliminadas deveriam, pelo menos ser atenuadas ao máximo. Inúmeras eram as falas que apontavam a busca pelas cirurgias como uma forma de buscar apagar "os deselegantes traços do envelhecimento".

Contudo é necessário cautela. Não há como pensar que as mulheres vivem todas essas transformações de forma passiva e acrítica. Como todo culto, como toda moda, o impacto da moda do culto ao corpo sobre a sociedade, só pode ser detectado a partir da compreensão da maneira como seus ditames são interpretados pelos indivíduos que, no interior de diferentes grupos sociais, Ihes emprestam significados próprios. Por isto não acreditamos na submissão total do sujeito aos dispositivos culturais, daí primeiro abordar o que percebemos como resistência do sujeito feminino nesta busca pela melhoria estética. Novamente, pedimos aos leitores que tenham em mente a diversidade cultural e nossa herança patriarcal.

\section{A estética como resistência}

Aprisionadas durante séculos no lugar da mãe, da santa e da esposa, podemos pensar esta busca por um corpo mais jovem e mais atraente como uma nova erótica feminina, onde a menopausa pode significar uma ruptura com a associação mulher/atividade reprodutiva.

A representação psíquica do corpo feminino durante os ciclos biológicos, e seu lugar na constituição das posições subjetivas acessiveis às mulheres na contemporaneidade não podem ser deixados de lado. Da mesma forma não podemos nos esquecer da relação entre a feminilidade e a maternidade e a importância do recalque da sensorialidade primária na configuração da subjetividade feminina hoje.

O corpo feminino, pensado numa cultura falocêntrica, foi percebido e significado, ao longo da História, como insuficiente em relação ao masculino. Ao mesmo tempo, essa "insuficiência" teria como contraponto o poder da maternidade, sendo a mulher identificada como geradora de vida e de morte, desde os primórdios da civilização.

Seu corpo, desconhecido e ameaçador, deveria por isso ser domesticado. A tática disciplinadora desenvolvida pela cultura ocidental, desde a Idade Média, consistiu na exaltação da maternidade e em sua naturalização (Perrot,1984). Assim, a feminilidade foi sendo associada à maternidade e à função de procriar e educar os filhos, e a mulher que tentava ser feminina seguindo outros moldes frequentemente se apresentava aos médicos como louca - histérica ou psicótica. (Furtado, 2000) 
Sem dúvida alguma podemos pensar que no mundo contemporâneo a feminilidade pode ocupar outros espaços distintos da maternidade, contudo, não cremos que seja errôneo afirmar que esta ainda pareça ser uma das funções organizadoras desta categoria. Por esta razão, acreditamos ser a menopausa, momento do ciclo vital feminino em que cessa a atividade reprodutora, uma boa linha divisória para pensarmos a feminilidade em sua relação com a aparência física.

No Brasil é comum mulheres na menopausa relatarem sentir um vazio no corpo, como se o mesmo fosse oco. Tal sensação é sintetizada no provérbio/dito popular que apresentamos a seguir: mulher na menopausa vira homem!

É neste sentido, que enfatizamos que a busca por um novo corpo, como uma linha de fuga, pode representar um corpo em transformação contínua - um novo devir. De forma análoga, compreendemos nestes movimentos não uma ruptura, mas uma tentativa de que o mesmo não perca o seu caráter libidinal, afirmando, simultaneamente, o seu estatuto de corpo desejante.

Assumindo uma nova posição, a maturidade vai permitir a esta mulher a busca de um novo lugar de prazer, onde um corpo mais agradável tanto ao seu próprio olhar, como ao olhar do outro, lhe permitirá viver mais libertamente a sexualidade que, tradicionalmente, Ihe foi negada. Daí pensarmos em termos de resistência.

Mas, por estarmos tratando de sujeitos, há também o outro lado da moeda.

\section{Um corpo que busca um sentido}

Freqüentemente, a mídia, com grande apoio do discurso médico, oferece estímulos para que as mulheres recorram a expedientes que visariam evitar a constatação de mudanças que incidem sobre sua subjetividade, valendo-se do estágio atual de evolução das ciências biotecnológicas.

Como aponta Gromann (2007) no limiar da perda da capacidade procriadora, a mulher se vê as voltas com um enigma envolvendo seu corpo: diminuição hormonal, aumento libidinal (Freud 1912/1969), um corpo estrangeiro, que não obedecendo aos ciclos esperados, lança-a a um terreno desconhecido, angustiante e povoado por muitas fantasias. 
Neste cenário, o corpo feminino torna-se um corpo em transição. Contudo, para que este corpo possa efetuar esta passagem do corpo-mãe, para um novo corpo erótico é necessário um trabalho de elaboração do luto deste corpo-mãe.

Mas isto não ocorre necessariamente. Há um silêncio imposto aos órgãos em sua significação mais profunda -, como se estivéssemos diante de um corpo sem narrativa. Como aponta Birman "o enfermo como subjetividade foi sendo progressivamente excluído e silenciado da cena da enfermidade... excluído que era de qualquer implicação no processo de adoecimento" (2003:10).

Freqüentemente o que iremos então observar é o total descolamento do sujeito com o seu sintoma. O corpo, tratado a penas como organismo; corpo da ordem da natureza, do qual a medicina se ocupa com grande maestria.

Para os desconfortos do envelhecimento, a reposição hormonal. Para os sinais da passagem do tempo, as cirurgias e a cosmetologia. A menopausa, vista como algo "natural" é reduzida ao âmbito biológico, com seus sintomas "desagradáveis", facilmente suprimíveis com o tratamento adequado.

O surgimento das inúmeras práticas corporais e técnicas de modelagem física parece ancorado na mesma idéia de autonomia e auto-regulação do sujeito com relação ao seu corpo, reforçando, com isso, um comportamento de aversão com relação aos corpos que desviam do padrão estético dominante. É interessante notar como os discursos que normatizam o corpo, científico, tecnológico, publicitário, médico, etc. vão, pouco a pouco, tomando conta da vida simbólica/subjetiva do sujeito (Vilhena \& Novaes, 2003).

A beleza moderna, longe de prometer uma compensação narcísica à mulher, agudiza sua frustração e sua impotência face à potência da imagem. A mulher passa a ser mais algoz de si mesma em relação à beleza. Prosaicas "Mouras-Tortas" como afirma Costa (1985) desenvolvem uma relação persecutória do ego com o corpo, onde cada ruga ou cada grama a mais levam-na ao desespero. “Este corpo, insaciável, não é mais para o ego objeto que realiza o desejo de prazer. É o objeto que o ego tenta dominar e controlar, à custa de um crescente sentimento de culpa e de uma ansiedade infindável” (idem, p. 187).

Segundo Ehremberg (1998), esta ansiedade é fruto de um sentimento constante de insuficiência e fracasso. Para o autor o paradigma contemporâneo não é mais o da repressão sexual, objeto de estudo para Freud na classificação das neuroses. Ao contrário, é fruto da disciplina internalizada que provoca um falso sentimento de autonomia. 
A produção de um sujeito autônomo e, simultaneamente, responsável pela sua aparência, como sinalizou o autor, forja um determinado tipo de subjetividade que gera um mal-estar definido pela sensação de estar-se aquém dos ideais.

Para ser eficaz a regulação deve ser devidamente incorporada, não operando apenas em sua dimensão social. De tal forma que, instaure no sujeito o sentimento de culpa e falta de caráter, pois aponta para um agenciamento inadequado das potencialidades individuais. Em síntese, se antes o poder era externo passou então a ser responsabilidade do sujeito saber agenciá-lo.

É esta narrativa que muitas vezes escapa na busca da mulher por um outro corpo. Reduzida à uma questão de vaidade, deixam-se de lado todos os aspectos subjetivos envolvidos no processo de envelhecimento. Com isso, elas evitariam se defrontar com o desafio de significar seus corpos de forma diferenciada daquela em que foram pensados até muito recentemente.

Se por um lado a cultura impõe de forma radical uma estética onde não há lugar para a velhice, é preciso estar atento à medicalização que retira do sujeito a sua implicação em seu sintoma, em seu pathos, que dificilmente será transformado em questão, posto que será magicamente removido através de uma intervenção cirúrgica, de uma medicação adequada ou de um tratamento rejuvenescedor (Vilhena, Novaes, \& Medeiros, 2006).

Ora, sabemos que uma coisa é a representação de corpo; outra é o corpo pulsional, corpo real, situado para além do representacional. O corpo pulsional - enquanto uma categoria - distingue-se tanto do corpo simbólico como do corpo biológico, sem, no entanto, excluí-los. E este precisa de uma morada.

Nada mais pertinente para ilustrar do que a história de Antígona em sua luta para sepultar o irmão Polinices. Por isto Lacan (1974:19) vai afirmar que o corpo biológico, mesmo morto, permanece incorporado pelo simbólico, não se transformando em carniça.

Roudinesco alerta que o sujeito moderno, "condenado ao esgotamento pela falta de uma perspectiva revolucionária, busca na droga, na religiosidade, no higienismo ou no culto ao corpo perfeito o ideal de uma felicidade impossível" (2000: 19).

Na maturidade feminina, como aponta Grosman, "a mulher ao transgredir a sua função reprodutora da espécie, passa a ter que se incluir em um novo lugar na polis, numa nova posição erótica e, para tanto, necessita realizar um trabalho psíquico que lhe outorgue uma abertura ao jogo objetal “(2007, 209).

Por esta razão acreditamos que as transformações corporais não possam vir desacompanhadas de suas narrativas. Quantas pessoas há em cada corpo? De quantas 
partes é feita uma pessoa? Habita aqui alguém inteiro? O que falta a uma pessoa? E a outra pessoa, é parte de mim? O outro que não tenho faz parte de mim? Uma pessoa é feita de quantas histórias -, quanto dos outros preciso em mim?

O corpo da mulher vem sendo considerado enigmático devido aos múltiplos sentidos 92 para os quais se abre, quando a posse de alguns elementos fálicos Ihe é socialmente permitida. Em nossa compreensão, mais do que um enigma (Freud), o feminino é um corpo que, considerado como pulsional, está em constante construção.

A exacerbada valorização da juventude que tem como conseqüências inúmeros investimentos tecnocientíficos objetivando uma interdição do envelhecimento parece, pelo menos imaginariamente, buscar a erradicação ou o afastamento da morte. E esta (exacerbação) atinge majoritariamente as mulheres (Vilhena \& Novaes, 2006).

Segundo Tucherman (2004) "ser-se aparentemente jovem quando se é mesmo jovem é, digamos assim, natural. O desafio e a promessa são a de ser aparentemente jovem, quando não mais o seríamos se deixássemos a natureza seguir o seu curso. Aliás, o que se promove é mais do que a aparência jovem: são os atributos da juventude que se deseja eternizar" (p. 141).

Acreditamos que os ciclos biológicos são momentos em que há uma rearticulação das marcas sensoriais, constitutivas das imagens corporais que servem de base para o eu. Nas mulheres, esses momentos seriam deflagradores da percepção de seu corpo com um funcionamento cíclico, que poria em questão a feminilidade, como uma aquisição consumada e definitiva. Tal articulação já feita por Freud em 1912, no artigo Tipos de desencadeamento da neurose, adquire novas tinturas na contemporaneidade: mais do que objeto de desejo, o corpo na contemporaneidade passou a ser objeto de design como a ponta o artista plástico Sterlac. O mote capitalista: tempo é dinheiro passa a ser invertido: dinheiro compra tempo. Ou seja, dinheiro, imaginariamente, compraria o apagamento das marcas do tempo.

Tucherman indaga se não estaríamos vivendo um momento de extrema dedicação a uma estética que seria também uma erótica e uma dietética. Para a autora a artificialização é hoje a presença da técnica e suas múltiplas misturas em nossas vidas. Mas é também, como menciona Courtine (1995), um "puritanismo ostentatório" nesta cultura do corpo, condição sine qua non para a premissa desta juventude como paradigma não apenas estético, mas também morfológico e ético. O que observamos então é que em nome de um movimento cientificista de controle da fisiologia, que desconsidera a subjetividade, parece que a menopausa é, para o discurso médico, uma experiência a ser evitada. Seus efeitos, da mesma forma, podem e devem ser reduzidos às suas conseqüências fisiológicas. 
No entanto, como a clínica nos mostra, esta prática não consegue evitar a angústia frente à finitude e à morte, e, principalmente, face à ameaça - mortífera para o eu - da perda do amor com que se defrontam as mulheres nesse momento.

Costuma-se fazer, então, um apelo ao discurso médico para dar um sentido ao desconforto psíquico, na tentativa de evitação da perda do lugar de objeto de desejo da juventude.

Como aponta Novaes (op.cit) em sua pesquisa "todas as nossas entrevistadas, parecem encarar as práticas corporais como uma forma de tornar seus corpos mais sedutores, e o horror ao envelhecimento torna-se bastante evidente. Para preservar a juventude e, conseqüentemente a boa aparência tudo deve ser tentado" (2006, p. 224).

O sentimento é bem ilustrado na fala de várias entrevistadas:

"Meus filhos dizem que estou ótima, que tenho tônus de garota... Acho enveIhecer cruel".

"Gostaria de ser de tipo de mulher que acredita que a idade é um estado de espírito. Sinceramente... adoraria que o espelho me dissesse que a minha imagem é um mero reflexo do meu estado de humor... As minhas rugas estão lá, impreterivelmente, todo dia de manhã quando eu acordo e me olho no espelho - elas me dão bom dia!".

Talvez o envelhecimento seja o monstro que a medicina atual tenta combater. Este acena como o grande mal contra o qual os discursos médicos e científicos se empenham em retardar - a morte, a dor, o sofrimento e a finitude, em suma, tudo aquilo que caracteriza a condição humana.

\section{Conclusão}

O corpo, nos dizia Levi Strauss, é a melhor ferramenta para aferir a vida social de um povo. Ao corpo cabe algo muito além de ocupar um espaço no tempo. Cabe a ele uma linguagem que se institui antes daquilo que denominamos "falar", que se exprime, evoca e suscita uma gama de marcas e falas implícitas.

O corpo fala e as marcas nele feitas também. A questão estética se impõe como forma e fôrma e o que é belo pode vir a ser feio. Da mesma maneira, o belo pode instituir um padrão de feiúra. No fundo vivemos no fio de uma navalha, fio este que tenuamente separa feiúra e beleza.

Mas é preciso cuidado. Se os discursos sobre o corpo jamais são neutros, é também necessário evitar a postura unívoca de vê-lo apenas como disciplinado, obedecendo 
cegamente às regras do look, no sacrifício ascético em prol da manutenção da juventude e da bela forma.

Uma vez que o corpo nunca é totalmente apreendido pelos dispositivos culturais, que possibilitem sua submissão completa às expectativas sociais, a "feiúra" ou o

94 "estranho", muitas vezes poderão ser tomados como uma mensagem, cuja força reside, justamente, na sua surpreendente apresentação.

Neste sentido, as práticas corporais podem ser compreendidas em um cenário de indiferenciação, na estetização da vida cotidiana, de sujeição ao discurso do outro, mas também, como uma contestação, como problematização do estatuto do corpo na contemporaneidade. De qualquer forma, o corpo está em cena sem que haja qualquer possibilidade de predizer o futuro e seus limites.

Por isto não se trata de condenar ou banir do horizonte feminino as cirurgias plásticas, os tratamentos rejuvenescedores ou as reposições hormonais. Certamente eles podem nos trazer grandes benefícios e muito prazer. Contudo, restringir o inexorável do envelhecimento a um puro "desequilíbrio hormonal", equiparando-o a uma doença ou a uma questão meramente estética é repetir uma fórmula de controle sobre a mulher, presente na modernidade, que amordaça a singularidade da produção de sentido.

Como bem ressalta a cantora popular Rita Lee "que poder é esse que a família e os homens têm sobre o corpo das mulheres? Ontem, para mutilar, amordaçar, silenciar. Hoje, para manipular, moldar, escravizar aos estereótipos.

Na modernidade, a estética encontra-se vinculada a diversas formas de sociabilidade, impondo sua ordem como uma instância reguladora que abarca um número, cada vez maior, de contextos e formas sociais.

O médico, em sua relação com o corpo, tem uma atitude do homem que está desmontando uma máquina (Lacan 1985/1955:97). O corpo que interessa à psicanálise é, contudo, bastante distinto daquele da medicina: não se trata de um organismo vivente, agregado de carnes e órgãos, mas de um corpo que fala, goza, silencia e ensurdece, sempre à espera de um deciframento.

Trata-se, por isto, de articular cada uma destas práticas corporais aos discursos produzidos pelo corpo. É na busca de um sentido e de uma narrativa que signifique as distintas experiências subjetivas que o sujeito não se torna um estrangeiro em seu próprio corpo. 


\section{Referências Bibliográficas}

Birman, J. (1999). Mal-estar na atualidade. A psicanálise e as novas formas de subjetivação. Rio de Janeiro: Ed. Civilização Brasileira.

Costa, J.F. (1985). Violência e Psicanálise. Rio de Janeiro: Ed. Graal.

Courtine, J.J. (1995) Os Stakanovistas do narcisismo. In: Sant'Anna, D.B. (Ed) Políticas do Corpo: Elementos para uma história das práticas corporais (pp. 60-92). São Paulo: Ed. Estação Liberdade.

Eco, H. (2004). Histoire de la Beauté. Paris: Ed. Famarion.

Ehremberg, A. (1998). La fatigue D'être soi : Dépression et Société. Editions Odile Jacob: Paris.

Freud, S. (1969). Tipos de Desencadeamento da Neurose (trad. Jayme Salomão). Rio de Janeiro: Edições Standard Brasileira .

Furtado, A.M. (2000). Um corpo que pede sentido: um estudo sobre a mulher na menopausa. Dissertação de mestrado não publicada. Dept de Psicologia, PUC-Rio.

Gil, J. (1988). Corpo, espaço e poder. Lisboa: Ed. Litoral.

Gromann, R.M.G. (2007). A política do erotismo na maturidade feminina: um estudo sobre as relações entre os estados hipocondríacos e melancólicos. Revista Latinoamericana de psicopatologia fundamental, (Vol.X), 2, 203-218.

Lacan, J. (1974). Television. Le Champ freudien. Paris: Seuil.

Lacan, J. (1988). The Seminar Book II: The Ego in Freud's Theory and in the Technique of Psychoanalysis. Ed. Jacques-Alain Miller, Tradução Sylvana Tomaselli. New York and London: Norton. (obra original publicada em 1954-1955).

Le Breton, D. (1985). Corps et Sociétés: Essai de Sociologie et Anthropologie du Corps. Paris: Lib. des Meridiens.

Malysse, S. (1997). A la recherche du corps ideal: culte féminin du corps dans la zone balnéaire de Rio de Janeiro. Cahiers du Brésil Contemporain, 31, 157-174.

Novaes, J. (2006). O intolerável peso da feiúra. Sobre as mulheres e seus corpos. Rio de Janeiro: Ed. PUC/Garamond.

Novaes, J. V. (2003). Da cena do corpo ao corpo em cena. Estética feminina e cirurgia plástica. In Castilho, K; Galvão, D. (Eds.). A moda do corpo O corpo da moda, (pp. 150-158). São Paulo.

Perrot, P. (1984). Le corps feminin: le travail des apparences, XVIII-XIX siècle. Paris: Editions du Seuil.

Remaury, B. (2000). Le beau sexe faible. Les images du corps féminin entre cosmetique et santé. Paris: Ed. Grasset \& Fasquelle.

Roudinesco, E. (2000). Por que a psicanálise? Rio de Janeiro: Jorge Zahar.

Tucherman, I. (2004). Forever Young: A juventude como Valor Contemporâneo. Revista Logos, Ano XI, 21, 134-150.

Vilhena, J. \& Novaes, J.V. (2003). Las enfermedades de la belleza: acerca de lo intolerable de la fealdad. Psicoanálisis y Hospital, (v. 12), 24, 38-43.

Vilhena, J. \& Novaes, JV (2006). Dormindo com o inimigo. Mulher, feiúra e a busca do corpo perfeito. In www.comciencia.br, n.78, LABJOR UNICAMP/SBPC.

Vilhena, J., Novaes, J.V. \& Medeiros, S (2006). A violência da imagem. Estética, o feminino e a contemporaneidade. Revista Mal-estar e Subjetividade, Vol.V, 1, 111-146. 


\section{The body and its narratives. Body culture and womens' ageing}

In the city of Rio de Janeiro there is an increasing number of mature women who have been seeking gyms and plastic surgery clinics in search for a young appearance as well as a body considered appropriate and attractive. The exacerbation of the body culture in our city has been driving a great contingent of women to radical body practices. Motivated by the media and by the medical speech these women are led to face the aging process, just as an hormonal or aesthetic matter, leaving aside the subjective aspects of aging. This article analyzes this frenzied search for the ideal body taking as conductive axis the existent differences between the body which is the object of medicine and the one which is the object of psychoanalysis. While the first one is basically organic the latter requires a narrative in order to implicate the subject in its own experience.

KEYWORDS: Body Culture; Menopause; Aging; Woman; Psychoanalysis. 